\title{
Exegese Medieval do Livro do Apocalipse: Algumas trajetórias de uma História da Interpretação
}

\author{
Medieval Exegesis of the Book of Revelation: \\ Some trajectories of a History of Interpretation
}

Pedro Paulo Alves dos Santos

\section{Resumo}

Neste espaço de 'compendium' joanino intento expor algumas das características das práticas literárias e exegéticas em torno do livro do Apocalipse no âmbito da tradição latina e medieval. Perguntamo-nos neste contexto, quem eram os produtores de interpretação apocalíptica (monges, bispos e eruditos)? Em que sociedade se produziu esta busca e que necessidade se impunha de interpretar e atualizar as profecias do último livro do Cânon? Quem são os leitores a quem se dirige uma produção tão específica e inquietante? Quais comentaristas e comentários se ocuparam do Livro do Apocalipse na chamada Idade Média?

Palavras-chave: Exegese Bíblica. História da Interpretação. Livro do Apocalipse. Exegese Medieval.

\section{Abstract}

In this space of 'compendium' Johannine attempt to expose some of the characteristics of literary and exegetical practices around the book of Revelation within the framework of the Latin and medieval tradition. We ask ourselves in this context who were the producers of apocalyptic interpretation (monks, bishops and scholars)? In what society was this quest produced, and 
what need was there to interpret and actualize the prophecies of the last book of the Canon? Who are the readers to whom such a specific and disturbing production is directed? Which commentators and comments have dealt with the Book of Revelation in the so-called Middle Ages?

Keywords: Biblical Exegesis. History of Interpretation. Book of Revelation. Medieval Exegesis.

\section{Introdução}

Homenagem ao Grande Mestre e Amigo + UGO VANNI, SJ

(Roma 28.09.2018)

Um perfil histórico das práticas e produções literárias na Idade Média implica na centralidade do conceito de "Exegese". Termo grego que é atestado já no período Bizantino e em toda a Idade Média que não será atestado senão a partir do século XVII em língua inglesa, no século XVIII em língua castelhana e em 1695 no âmbito francófono. ${ }^{1}$ Portanto a expressão ou atividade intelectual denominada pelo termo "exegese" designava uma prática erudita de humanistas. No contexto ocidental latino não existia até então um termo para se designar tais práticas, a não ser pelo termo lectio, ${ }^{2}$ através de definições como commentum, tractatus, expositio. Já na exegese bíblica na Idade Média tardia (séc. XIII) era uma atividade subordinada às artes liberais e dos gramáticos, sustento para a produção teológica. Mas, a "coisa" existia antes do nome. Se se percorre a literatura cristã desde as origens a exegese bíblica aparece exuberante e onipresente. A exegese bíblica seria um gênero literário específico. ${ }^{3}$ Neste sentido, por exegese, entende-se um corpus de escritos (comentários e glosas) dedicados à Bíblia e à sua interpretação. Daqui se desenvolve a interpretationis regulae. Esta atividade está bem comprovada nas obras de Ticônio (séc. IV),

\footnotetext{
${ }^{1}$ Muito interessante o texto de LOBRICHON, G., L'Esegesi Biblica, p. 355-381.

${ }^{2}$ SANTOS, P. P. A., Aspectos teológicos da espiritualidade de Santa Gertrudes, p. 47-66.

${ }^{3}$ Leitura provocadora e estimulante do artigo de FONTAINE, J., Comment doit-on appliquer la notion de genre littéraire à la Littérature latine chrétienne du IVº siècle?, p. 53-73.
} 
com suas famosas 7 regras, ${ }^{4}$ reportadas por Beda, o Venerável (VIII séc.) ${ }^{5}$ em seu comentário ao Apocalipse e ainda no séc. XII no Didascalion de Hugo de S. Victor (1114), ${ }^{6}$ como o fora em Agostinho e Jerônimo. No que se refere à exegese bíblica latina e medieval, ${ }^{7}$ não se concebia uma pesquisa científica completamente desvinculada de implicações sociais. A exegese bíblica foi criada, como qualquer gênero literário, para satisfazer um público, e não escapava desta função, pois, aqueles que a praticavam se colocavam declaradamente a serviço de uma comunidade espiritual. Portanto, expor alguns elementos da "exegese" do Apocalipse implica em revisar a produção medieval da interpretação literárioteológica e suas implicações e características sócioeclesiais.

\section{A Exegese Medieval do Apocalipse}

A Exegese do Apocalipse ${ }^{8}$ usufrui durante toda a Idade Média de alguns grandes mestres. ${ }^{9}$ Não será o texto mais comentado, mas receberá particulares atenções da produção exegética deste período. ${ }^{10}$ Cabe-nos explorar alguns aspectos do desenvolvimento dos "Comentários" medievais sobre o Livro do Apocalipse. Parte-se sempre do texto do donatista Ticônio, que em suas regulae interpretationis inspirou a história da hermenêutica de textos apocalípticos. Neste sentido, se entende a produção tardo-antiga de Vittorio

${ }^{4}$ SIMONETTI, M., Ticonio e l'interpretazione dell'Apocalisse, p. 289-305; FREDRIKSEN, P., Tyconius and Augustine on the Apocalypse, p. 20-37. Muito interessante e esclarecedor o artigo de MARRONE, P., La continuità esegetica che caratterizza le opere di Ticonio ovvero l'applicazione delle "Regole" nel "Commento all'Apocalisse", p. 253-270.

${ }^{5}$ BEDA, O VENERÁVEL, Commento all'Apocalisse.

${ }^{6}$ PIAZZONI, A. M., L'Esegesi Vittorina, p. 239-256.

7 XXI INCONTRO DI STUDIOSI DELL'ANTICHITÀ CRISTIANA. Cristianesimo Latino e cultura Greca sino al sec. IV; Sobre ambientes e a produção livresca tardo-antiga: CATALBIANO, M., Litterarum Lumen; SIMONETTI, M., L’Esegesi patrística in Occidente, p. 7-22. ${ }^{8}$ GUGLIELMETTI, R. E., L'Apocalisse nel Medioevo.

${ }^{9}$ MCGINN, B., John's Apocalypse and the Apocalyptic Mentality, p. 3-19. Sobre uma tradição medieval de leitura bíblica e apocalíptica, chama a atenção aquelas da tradição Franciscana: BURR, D., Mendicant Readings of the Apocalypse, p. 89-104. Mais amplamente: POTESTÀ, G. L., I frati minori e lo studio della Bibbia, p. 269-285.

${ }^{10}$ EMERSON, R. K., The Apocalypse in Medieval Culture, p. 293-332. A obra de G. Cavallo continua indispensável para o estudo de leitura, leitores e livros: CAVALLO, G., Libri e lettori nel Medioevo; CAVALLO, G., Le Biblioteche nel mondo antico e medieval; CAVALLO, G.; CHARTIER, R., Storia della Lettura. Interessante também a leitura de CHARTIER, R., Uma Variante: a edificação Hagio-gráfica, p. 266-280; FOSSIER, R., As Pessoas da Idade Média; FOSSIER, R., O Trabalho na Idade Média; LE GOFF, J., A Idade Média e o Dinheiro, 2014. 
de Pettovio (séc. IV), Agostinho (séc. V), Jerônimo (séc. V) até os Medievais. Deste modo, deve-se discutir o papel do Apocalipse na sociedade medieval com um olhar voltado para a significação teológica do texto e a sua recepção. ${ }^{11}$ Em particular sua relevância se referia ao acentuado debate em torno dos "milenarismos" $" 12$ que agitavam as sociedades medievais. Ticônio, Agostinho e Jerônimo produziram trabalhos hermenêuticos nos quais uma potente forma "anti-milenarista" 13 se impõe às leituras "fantásticas" do livro, como se pode constatar em parte na obra de Joaquim de Fiore (séc. XII). Aqui se percebe que não há uma leitura unívoca do texto apocalítico. McGinn indica ao menos três perspectivas/abordagens/enfoques para a sistematização histórica da interpretação do Apocalipse. ${ }^{14}$

\section{A) Perspectiva profético-linear}

A primeira tem a leitura do livro como uma perspectiva/abordagem/ enfoque profética linear, como se projetasse uma história sequencial entre a visão do autor no passado e seu cumprimento no fim dos tempos. Na Idade Média destaca-se Nicolau de Lira, entre outros. Em Lutero ${ }^{15}$ em época moderna, tem-se um bom exemplo de recepção desta perspectiva.

B) Apocalipse como um "tratado teológico"

A segunda perspectiva/abordagem/enfoque (approach) tem visto o Apocalipse como um "tratado teológico" (theological Treatise) organizado a partir de alguns esquemas não-históricos. Agostinho influenciou muitos

${ }^{11}$ HERZMAN, R. B., Dante and the Apocalypse, p. 398-413; MAGGIONI, G. P., La Bibbia nella Lettura Visionaria, p. 377-388. Ainda sobre o mesmo ângulo: SANTI, F., La Bibbia e la Letteratura profético-apocalittica, p. 389-408; LERNER, R. E., The Medieval Return to the Thousand-Year Sabbath, p. 51-71. Interessante o estudo de MCGINN, B., Visions of the End.

${ }^{12}$ Muito se escreveu sobre esta questão de ordem escatológica. O texto de Ap 20 inspirou a exegese de muitos autores ao longo do período tardo-antigo e medieval: MAGGIONI, G. P., La Bibbia nella Lettura Visionaria, p. 377-388. Seu representante mais produtivo numa perspectiva milenarista permanece, talvez, o Abade de Fiori (séc. XII).

${ }^{13}$ Muito estimulante o pequeno artigo de NARI, M. C., La Bibbia ed Eretici nel Pieno Medioevo, p. 409-424. REVENTLOW, H. G., Un Monaco in attesa delo Spirito, p. 236-254.

${ }^{14}$ MCGINN, B., John's Apocalypse and the Apocalyptic Mentality, p. 17. Um artigo atualizado sobre a interpretação do Apocalipse: BIGUZZI, G., In cerca di punti ondivisibili per per l'interpretazione dell' Apocalisse, p. 501-528.

${ }^{15}$ HOFFMAN, H.-U., Luther und die Johannes-Apokalypse. 
autores medievais a assumir esta perspectiva. Esta "leitura" do Apocalipse parece bem viva ainda hoje. ${ }^{16}$

C) Abordagem "cíclica" ou leitura "recapitulativa"

Finalmente, existe uma perspectiva/abordagem/enfoque "cíclica" ou leitura "recapitulativa" do Texto, no qual o texto (Apocalipse) é visto como uma narrativa profética do que está por vir antes do final, mas sob a forma de complexas repetições, ou narrações alternativas da mesma mensagem. Esta abordagem se encontra inaugurada por Victorinus de Pettau (séc. III), Bispo da Grande Perseguição, ulteriormente por Joaquim de Fiore (séc. XII). Muitos recentes intérpretes, entre aqueles que adotam o método histórico-crítico, estruturalista ou teorias hermenêuticas como pontos de vista, acreditam que o Apocalipse foi construído de acordo com model recaptulative, isto é, com modelos de recapitulação. Em cada um destes modelos os autores se dividem, como por exemplo, ao utilizar, sobretudo um simbolismo numérico, que se repete constantemente, como um setenário. ${ }^{17}$

\section{O Apocalipse na Cultura Medieval}

O poder imaginativo de seus recursos visuais, a beleza poética de sua liturgia celeste e sua representação simbólica da memorável batalha cósmica entre o bem e o mal, não só fascinou artistas medievais, mas também uma vasta gama de poetas, historiadores, pregadores e teólogos. Na verdade, com a culminação do cânone cristão, o Apocalipse foi considerado como "a flor da teologia". Existe ainda muito a ser pesquisado em relação à influência do Apocalipse sobre a Cultura Medieval, para além dos estudos joaquinitas (De Fiore) e as suas expectativas escatológicas. ${ }^{18}$ Tratar-se-ia de produzir uma

${ }^{16}$ FARRER, A., A Rebirth of Images; ELLUL, J., Apocalypses. The Book of Revelation. BORNKMANN, G., Die Kompositon der apokalyptischen Visionen in der Offenbarung Johannis, p. 132-149. Sobre estas perspectivas antigas e modernas: BIGUZZI, G., In cerca di punti ondivisibili per l'interpretazione dell'Apocalisse, p. 503-504.

${ }^{17}$ De leitura indispensável os artigos do nosso Mestre: VANNI, U., Il Simbolismo nell'Apocalisse, p. 461-505; VANNI, U. Linguaggio, Simboli ed esperienza misitica nel libro dell'Apocalisse, p. 473-501. Em uma perspectiva de análise antropológica: VANNI, U., L'Uomo dell' Apocalisse.

${ }^{18}$ Não se podem ignorar os influxos da "escatologia" portuguesa medieval pela construção do mito de Dom Sebastião no Brasil: PINHO, A., Quinto Império, messianismos, p. 121-131; 
verdadeira historiografia da exegese iconográfica medieval. Com isso se pode construir uma tipologia de imagens apocalípticas que compõem uma verdadeira "gramática imagética" do Apocalipse, que perpassa a cultura e a mentalidade medievais.

Esta gramática é composta por ao menos três elementos integrados em diversos estágios entre si: o primeiro são imagens e motivos, ordinariamente objetos e simples ações; segundo, uma investigação de suas associações e lugares na paisagem visionária do Apocalipse; e por fim, uma análise dos agentes apocalípticos que manipulam estes objetos, manuseiam estes motivos e se movem nestas paisagens.

\subsection{Imagens e Motivos}

O primeiro estágio no estabelecimento de uma "gramática imagética" apocalíptica ${ }^{19}$ deve concentrar-se sobre "objetos" literários individuais, como por exemplo, o livro (tò biblíon) $)^{20}$ presente em diversas formas dentro do Apocalipse: livro das profecias, livro selado e aberto, escrito fora e dentro, pequeno livro devorado. São Jerônimo, entre outros, explorou este tema em diversos contextos. ${ }^{21}$ Outro tema é a prisão do dragão (Ap 20,1-2). Esta imagem ou tema justificará duas das maiores tradições da exegese apocalíptica: uma abordagem eclesiológica (combate histórico contra o Mal) e outra de natureza escatológica $\left(\right.$ profecias do fim dos tempos $=$ milenarismos) ${ }^{22}$

\subsection{Lugares imagéticos}

Um segundo estágio no desenvolvimento da "gramática imagética"

TEIXEIRA, A. B., Profecia e Escatologia em António Vieira, p. 11-21. Numa tentativa de estabelecer a herança 'joaquinita' em Portugal: ROSSATO, N. D.; MARTINI, M., Milenarismo em Joaquim de Fiore e Antônio Vieira, p. 264-28; ZIERER, A. M. S.; RIBEIRO, J. N. L. Messianismo, escatologia e pedagogia cristã na crônica D. João I, p. 30-43.

${ }^{19}$ Sugestivo o letramento "imagético" na era digital em que estamos mergulhados, arte que não depende só dos olhos: MANGUEL, A., Lendo Imagens.

${ }^{20}$ BAILLY, A., Biblion to, p. 359.

${ }^{21}$ JERÔNIMO, Epistola, VII,3.

${ }^{22}$ Uma leitura mais completa sobre a história da recepção do Livro (em suas imagens, léxico e teologia) durante toda a Idade Média: MCGIN, B., Visions of the End. Num expecto mais amplo: LOBRICHON, G., Gli Usi della Bibbia, p. 523-562. Mais especificamente no Apocalipse: LOBRICHON, G., La femme d'Apocalypse 12 dans l'exégèse du haut Moyen Âge latin, p. 407-439. 
do Apocalipse é o exame dos lugares ${ }^{23}$ destas imagens e motivos. No caso ainda do livro (de sete selos) quando aberto nos projeta no mais brilhante firmamento celeste. Neste campo a literatura dantesca da "Divina Commedia" repercute a imagética espacial de Ap 21,8. Assim, também o famoso texto "Visio Pauli", ${ }^{24}$ no qual se insere o leitor nos referencias celestes do "sétimo céu" paulino. Neste contexto mágico-espacial, emerge um tema apocalíptico tradicional na Idade Média: a nova Jerusalém (Ap 20-22) ${ }^{25}$ e Babilônia disputam o imaginário literário medieval. Petrarca em crítica ao papado em Avignon utilizará o simbolismo contrastante entre estas duas cidades. Ele aponta Avignon como a cidade medieval (séc. XIV) à moda de Babilônia, cativeiro do papado, e a sujeita a uma virulenta poética. Junto dele, Catarina de Siena participará desta desconstrução avignose em favor de Roma. ${ }^{26}$

\subsection{Agentes Apocalípticos}

O último nível de análise literária das intercalações entre o Livro do Apocalipse e a literatura se expressa no âmbito dos "agentes apocalípticos", como por exemplo, a Prostituta de Babilônia (Ap 17,1-2). Por isso, o terceiro estágio em uma gramática imagética do Apocalipse foca sobre a Prostituta e muitos outros agentes que povoam a paisagem do visionário de Patmos. Eles representam a luta entre o bem e o mal ao longo da história. Disso a literatura medieval é plena de textos. ${ }^{27}$ Em contraste com a Prostituta, a Mulher de

\footnotetext{
${ }^{23}$ A literatura dos "lugares/espaços" (settings) apocalípticos implica num estudo da imagética espacial: MANGUEL, A.; GUADALUPI, G. Dicionário de Lugares Imaginários. Sobre arte Medieval, na qual se alocou parte do cenário imaginário apocalíptico: DUBY, G., A Idade Média; LE GOFF, J.; SCHMITT, J.-C., Dicionário Temático do Ocidente Medieval.

${ }^{24}$ Sobre aspectos gerais de literatura "visionária" medieval: MAGGIONI, G. P., La Bibbia nella Lettteratura Visonaria, p. 377-388; JIROUŠKOVÁ, L., Die Visio Pauli. Wege und Wandlungen einer orientalischen Apokryphe im lateinischen Mittelalter. Unter Einschluß der alttsechischen und deutschsprachigen Textzeugen. BREMMER, J. N., The Visio Pauli and the Gnostic Apocalypse of Paul; SILVERSTEIN, H. T., Dante and the Visio Pauli, p. 397-399. OLIVAR, A., "Liber Infernalis" o "Visio Pauli"; GUGLIELMETTI, R. E., Deux témoins inédits de la Visio Pauli; DINZELBACHER, P., "Visio S. Pauli".

${ }^{25}$ SANTOS, P. P., ‘A (Nova) Jerusalém Celeste’ (Ap 21,9-22,5): Sobre a Cidade Escatológica, p. 357-386.

${ }^{26}$ RENNA, T., Avignon vs. Rome, p. 47-62.

${ }^{27}$ CAMPBELL, G., Antithetical Feminine-Urban Imagery and a Tale of two Women-Cities in the Book of Revelation, p. 81-108. SANTOS, P. P. A., A figura feminina de Apoc 12,1-6: o espaço insólitolincomum do seu papel estrutural em toda trama narrativa de conflito, p. 190-200.
} 
Ap $12,{ }^{28}$ assim como São Miguel, o Arcanjo, são leitmotiv de uma extensa literatura medieval. Havia também muito interesse na figura do profeta e vidente de Patmos que está no centro da narrativa apocalíptica, legitimando-a. Neste sentido se projetava na Idade Média tardia (séc. XIII-XV) esta figura única e ainda bem pouco estudada, o "profeta medieval". ${ }^{29}$

\section{Comentaristas e Comentários medievais do Apocalipse}

Neste contexto cultural da recepção literária direcionamos para a exposição (breve) da produção de alguns textos exegéticos: os Commenti e seus personagens, que se confundem com a história medieval da interpretação do Apocalipse. O que se percebe nesta lista é uma rede de intercessões, de reagrupamentos e recepções entre textos e comentadores formando uma autêntica tradição (transmissão) dinâmica, pois em cada período da exegese do Apocalipse, diversos âmbitos e contextos se relacionam através da leitura dialogada entre os diversos exegetas medievais.

\subsection{Victorinus de Pettau (séc. III)}

O mais antigo comentário latino conhecido é atribuído a Victorinus de Pettau $^{30}$ em torno de 300 d.C. Victorinus parece ter tomado sua chave inter-

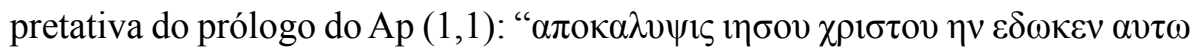

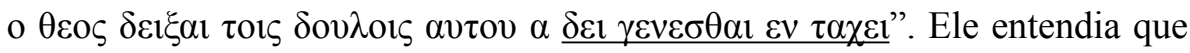
os eventos referentes à perseguição de Dioclesiano (90 d.C.) se realizavam no hodie ecclesiae.

\footnotetext{
${ }^{28}$ SANTOS, P. P. A., A figura feminina de Apoc 12,1-6, p. 190-200.

${ }^{29}$ Já se tornaram clássicos: DEVUN, L., Prophecy, Alchemy and the End of Time; TOUATI, Ch., Le problème de l'inerrance prophétique dans la théologie juive du Moyen Age, p. 169-187; REEVES, M., T The Influence of Prophecy in the Later Middle Ages; RUSSELL, J. B., Witchcraft in the Middle Ages; LERNER, R., Medieval Prophecy and Religious Dissent, p. 3-24; DAHAN, G., Lire la Bible au Moyen Âge. Um belo artigo sobre este tema: SANTI, F., La Bibbia e la Letteratura profético-apocalittica, p. 389-410. Nossos artigos: SANTOS, P. P. A., A Profecia Cristã no Novo Testamento, p. 71-102; SANTOS, P. P. A., O Apocalipse Cristão e os Rolos de Qumran, p. 133-156. ${ }^{30}$ MATTER, A. E., The Apocalypse in the Early Medieval Exegesis, p. 38-50; PANI, G., L'Anticristo nel Commento all'Apocalisse di Vittorino di Petovio, p. 677-702; PACZKOWSKI, K. M., Alcuni Aspetti Teologici dell'Apocalisse in Vittorino de Petovio, p. 171-206; DULAEY, M., Victorin de Poetovio. Sur L'Apocalypse. Um amplo estudo sobre estes campos na tradição greco-latina tardo-antiga: XVII INCONTRO DI STUDIOSI DELL'ANTICHITÀ CRISTIANA, Sogni, Visioni e Profezie nell'Antico Cristianesimo.
} 
A interpretação de Victorinus era essencialmente "quialística", isto é, referia-se ao reino milenarista de Cristo na terra, como um sinal do fim dos tempos. Esta leitura será reavaliada por outros comentadores, como Ticônio, Jerônimo e Agostinho. ${ }^{31}$ Em particular, estes quiseram ler o Apocalipse à luz da pax romana, após o edito de Constantino em uma chave eclesiológica integrativa entre Roma e a Igreja. ${ }^{32}$ A tendência dos futuros leitores/comentaristas medievais será a operação de uma "alegorização" do conteúdo, evitando assim, uma literalização de Ap 20. A partir de Jerônimo lê-se o texto de Victorinus à luz da teoria da "recapitulação", nesta perspectiva o Apocalipse apresenta uma série de eventos "tipológicos" que recorrem na história sagrada desde os Patriarcas, passando pelo desconhecido futuro da Igreja sobre a terra, até a Parusia. Para Victorinus as sete trombetas (Ap 8) ecoam do Império da Babilônia até o futuro, e o "Anticristo". Pode ser visto na história romana, como em quaisquer outros eventos até os nossos dias. ${ }^{33}$

\subsection{Ticônio (séc. V)}

A segunda fonte do antigo período medieval latino trata-se do Comentário de Ticônio, membro da igreja donatista. Seu trabalho entrou em suspeição, porém, influenciará os grandes leitores do Apocalipse, como Jerônimo e Agostinho, que vai citá-lo indiretamente em sua De Doctrina Christiana, não deixando de estabelecer, dada a condenação de Ticônio, uma relação complicada. ${ }^{34}$ Agostinho purificou Ticônio, assim como Jerônimo o fez com Victorinus de Pettau. Uma versão "catolizada" do Apocalipse de Ticônio em um manuscrito de um mosteiro italiano (Bobbio) mostra que o texto sobreviveu independente e que teria sido utilizado por Jerônimo em sua correção de Victorinus. Este comentário teria influência sobre uma plêiade de autores/comentadores medievais: Primasius (Norte da África), Caesarius (Gália), Beda (Irlanda), Ambrosio de Aupert (Benevento). O Comentário de Ticônio representou uma "tradição antiquialista" (= "antimilenarista"), com ênfase na

\footnotetext{
${ }^{31}$ MARUCCI, C., La canonicità dell'Apocalisse nel Primo Milennio, p. 649-666.

${ }^{32}$ SANTOS, P. P. A., Antigas Leituras do Apocalipse na Igreja Grega, p. 274-306.

${ }^{33}$ Tal abordagem da profecia do Novo Testamento, isto é, a ligação do momento histórico a um propósito transcendente, foi descrita por Marjorie Reeves como básico no ensinamento apocalíptico medieval (REEVES, M., The development of Apocalyptic Thought, 1984, p. 67).

${ }^{34}$ FREDRIKSEN, P., Tyconius na Augustine on the Apocalypse, p. 20-37; ainda sobre a obra hermenêutica de Ticônio: MARRONE, P., La Continuità exegética che caratterizza le opere di Ticonio ovvero l'applicazione delle Regole nel Commento al'Apocalisse, p. 253-270.
} 
Encarnação tão característica do seu século (antidoceta e antiariano), além de uma teoria da "recapitulação" exposta nas sete regras.

\subsection{Primasius (séc. VI)}

A antiga tradição é devedora de Primasius que pode ser arguido, mesmo antes de Victorinus, como o "start" medieval latino da exegese do Apocalipse. Isto é, o Comentário de Primasius é a confluência de outros dois textos "heterodoxos" (Victorinus/Ticônio) através da lente da "ortodoxia" (Jerônimo/ Agostinho).$^{35} \mathrm{O}$ comentário de Primasius representa bem, em sua problemática divisão do texto do Apocalipse, disposto em cinco partes, uma divisão que não se atém ao textus receptus, mas às suas escolhas de interpretação. Este problema estrutural é comum na exegese medieval porque os textos bíblicos ainda não tinham sido estandardizados em versículos, como muitos manuscritos que apresentam diversas quantidades de capítulos para o Apocalipse. Uma caraterística deste importante comentário é a sua interpretação eclesiológica. Ele entende, por exemplo o Cap. 12, a Mulher como a Virgem Maria, ao mesmo tempo em que cita os "hereges" de seu tempo, como aqueles que combatem a Mulher (Igreja), por interpretarem erroneamente a Encarnação do Verbo (Valentino, Apolinário, Nestório).

\subsection{Beatus de Liebana (séc. VII)}

Este intérprete do Apocalipse do séc. VII ${ }^{36}$ circulou sobretudo na Hispânia Medieval cristã. ${ }^{37} \mathrm{Na}$ Idade Média constitui o mais extenso comentário que chegou aos nossos dias, dividido em doze livros, cada qual com um longo prólogo. O contexto eclesial da Espanha medieval no qual esta obra se encontra escrita demanda lutas contra a heterodoxia em relação à divindade de Cristo, por parte do Bispo Elipantes de Toledo, além do início da dominação árabe/ muçulmana na Península Ibérica. Chama atenção neste contexto a combinação de uma exegese cristológico-eclesiológica do Apocalipse. Destacam-se o paralelo com a exegese do Cântico dos Cânticos, influenciado pela Moralia

\footnotetext{
${ }^{35}$ GRYSON, R., Les commentaires patristiques latins de l'Apocalypse (suite et fin), p. 484-502. ${ }^{36}$ WILLIAMS, J., Purpose and Imagery in the Apocalypse Commentary of Beatus of Liébana, p. 217-233; WILliAMS, J., The Beatus Commentaries and Spanish Bible Illustrations, p. 101-119.

${ }^{37}$ MCGINN, B., Beatus of Liébana, p. 77-80.
} 
de Gregório Magnus, das Cartas de S. Jerônimo, e o comentário de Lucas de S. Ambrósio. A associação do Apocalipse com Cântico dos Cânticos ${ }^{38}$ deriva da tradição da exegese alegórica no modo eclesiológico, standard na exegese monástica medieval. ${ }^{39}$

\subsection{Beda, o Venerável (séc. VIII)}

A tarda Idade Média na sua porção da cristandade latina fora marcada por uma intensificação em torno da sobrevivência da Igreja. Em pleno séc. VIII ocorre uma reviravolta na transmissão das fontes, isto é, os Padre da Igreja: assim como Primasius se torna um filtro para antigas interpretações, deste modo os comentários de Beda e Ambrosio Autpert incorporam Primasius e sua fontes e se tornam por sua vez, a maior fonte do Apocalipse para o período Carolíngio. ${ }^{40}$ A Explanatio Apokalypsis de Beda, o Venerável, é uma sofisticada análise do Apocalipse, um texto que reflete a história da Igreja sobre a terra, enquanto mantém um olhar atento sobre a grande imagem da história cósmica.

Em sua dedicatória, Beda faz uso das setes regras de Ticônio para descrever as sete idades (periochas) do mundo refletidas nos sete movimentos do texto: $1^{\circ}$ periodo $)$ o Apocalipse fala das sete igrejas $(1,1-3,21) ; 2^{\circ}$ periodo) marcado pelos quatro animais e abertura dos sete selos que revelam os futuros conflitos e vitórias da Igreja $(4,1-8,1) ; 3^{\circ}$ periodo) sob a forma de sete anjos tocando as trombetas, descreve as esperanças futuras da Igreja $(8,2-11,19)$; $4^{\circ}$ periodo) abre as obras e as vitórias da Igreja sobre a figura de uma mulher dando a luz o dragão que a persegue $(12,1-15,4) ; 5^{\circ}$ periodo $)$ é o periocha das sete pragas deverão infestar a terra $(15,5-16,21) ; \sigma^{\circ}$ periodo $)$ é a condenação da grande prostituta, que é o império ímpio $(17,1-20,15) ; 7^{\circ}$ periodo $)$ se verá a nova Jerusalém, adornada como noiva do Cordeiro, descendo do céu (21-22).

\footnotetext{
${ }^{38}$ MATIS, H. W., The Song of Songs in the Early Middle Ages, 2019.

${ }^{39}$ PARMEGIANI, R. F., Leituras Medievais do Apocalipse: Comentário ao Beato de Liebana, p. 107-125. Este artigo analisa as possibilidades de leitura e os usos sociais para o livro do Apocalipse na Alta Idade Média Hispânica. Para tanto, buscou-se mostrar a relação entre o "mundo dos leitores" e o "mundo do livro", ou seja, as práticas da leitura e da escrita que permearam a produção, a circulação e a leitura desse documento. Ressalta-se, nesse contexto, a relação entre poder e escrita.

${ }^{40}$ Sobre a Exegese Carolíngia: BERARDUCCI, A., L'Esegesi della Rinascita Carolingia, p. 167-198.
} 


\subsection{Ambrosio de Aupert (séc. VIII)}

Este comentarista do período carolíngio (escrito entre 758/767 d.C.), nobre lombardo, produziu um comentário sobre o Apocalipse em dez volumes, que entre outras características relevantes, teve o mérito de confluir os grandes comentários tardo-antigos: Victorinus/Jerônimo, Tyconius e Primasius, além de muitas referências à De Civitate Dei de Agostinho e Moralia de Gregório Magno. No entanto a fonte mais visível é Primasius, que por sua vez representou uma "quotação" da tradição apocalíptica anterior. Segundo Matter:

Um estudo das fontes deixa claro que uma motivação para Ambrose Autpert era criar uma fusão suave de suas fontes; no entanto, sua própria seleção de textos bíblicos, especialmente de escritos epitalâmicos tais como os Cânticos dos Cânticos, Salmos e Efésios, focaliza o comentário sobre o tema especial, a Encarnação de Cristo e seu casamento espiritual com a Igreja. ${ }^{41}$

Em todo período Carolingio (séc. VIII-XI) em diversos comentadores do Apocalipse (Alcuino, Haimo de Auxerre, Beda, entre outros) mostra-se a contínua assunção do texto apocalíptico como uma alegoria da Igreja, em contínuo processo de purificação, assim eles criaram uma rede de interpretação eclesiológica a partir da confluência de comentários ao longo dos séculos.

\subsection{Joaquim de Fiore (séc. XII)}

Não se pode, mesmo que en passant', expor importantes comentaristas medievais do Apocalipse sem referir-se ao grande Mestre, o Abade Joaquim de Fiore. ${ }^{42}$ Sua influência sobre os autores que concluem o período medieval e até moderno foi enorme e permanente. Mesmo condenado pela Igreja à causa de algumas interpretações bíblico-teológicas, ele será sempre recordado como um exegeta e um teólogo escatológico do Apocalipse. A fama de Joaquim

\footnotetext{
${ }^{41}$ MATTER, E. A., The Apocalypse in the Early Medieval Exegesis, p. 48: um estudo das fontes deixa claro que uma motivação para Ambrose Autpert era criar uma fusão suave de suas fontes; no entanto, sua própria seleção de textos bíblicos, especialmente de escritos epitálmicos tais como os Cânticos dos Cânticos, Salmos e Efésios, focaliza o comentário sobre o tema especial, a Encarnação de Cristo e seu casamento espiritual com a Igreja.

${ }^{42}$ MCGINN, B. Joachim of Fiori, p. 126-142; SANTI, F., La Bibbia in Gioacchino da Fiori, p. 257-268; REVENTLOW, H. G., Un Monaco in attesa delo Spirito, p. 236-254.
} 
como expositor e profeta se espalhou amplamente no final do séc. XII. ${ }^{43}$

Durante sua vida, cronistas contemporâneos registraram algumas de suas atividades e explicações sobre Escritura profética. Entre seus escritos exegéticos, que tinham como característica principal uma fisionomia "monástica e mística" nos quais ele criticava a postura tardo-medieval, representada pelos Franciscanos e Dominicanos parisienses, marcada por um impulso racional e acadêmico da exegese, destaca-se o Expositio in Apocalypsin. ${ }^{44}$

No Expositio in Apocalypsim, Joaquim entra em grande detalhe para explicar totalmente os símbolos, visões e figuras do Apocalipse. Desde que Joaquim considerou o Apocalipse como a chave para entender toda a Escritura, o Expositio in Apocalypsim é essencial para toda a exegese bíblica de Joaquim.

$\mathrm{O}$ gênero da exegese profética de Joaquim está ligado diretamente à interpretação do livro do Apocalipse, dedicando-se o abade a revelar o significado hermético e simbólico dessa fonte importante para a gênese da mística medieval. O Expositio in Apocalypsim criará uma verdadeira escola de interpretação joaquimita que terá acolhida nos círculos "espirituais" da ordem franciscana, mas não deixará de ter sua influência também em outros lugares.

\section{Conclusão}

Este percurso medieval de exegese do Apocalipse nos apresentou, de um lado, a evolução do exercício da exegese dita medieval. ${ }^{45}$ Um período de gênesis da mentalidade latina, herdeira da grande patrologia grega ${ }^{46} \mathrm{O}$ aperfeiçoamento da arte de interpretar textos normativos para toda a Idade Média permanecia no topo das tarefas intelectuais, culturais (arte) e espirituais.

\footnotetext{
${ }^{43}$ RIEDL, M., O Messias coletivo, p. 57-80.

${ }^{44}$ A situação manuscrita deste escrito do Da Fiori encontra-se comentada em recente pesquisa de FERRI, M., Il commento all'Apocalisse dei Mss. Cremona. Uma visão ampla da influência Joaquinita, durante e depois da Idade Média: WANNENMACHER, J. E. (Ed.)., Joaquin of Fiori and Influence of Inspiration; ROSSATO, N. D., Evangelium eternum, p. 99-115; MARJORIE, R., Joachim of Fiore and the Prophetic Future; MCGINN, B. The Calabrian Abbot.

${ }^{45}$ Muito interessante o texto de LOBRICHON, G., L'Esegesi Biblica, p. 355-381. Leitura provocadora e estimulante o artigo de FONTAINE, J., Comment doit-on appliquer la notion de genre littéraire à la Littérature latine chrétienne du IV siècle?, p. 53-73. Indiscutivelmente indispensável: DE LUBAC, H., Exégèse médiévale, les quatre sens de l'écriture; HARTMANN, J., Exégèse Médiévale, p. 552-553; DE LA POTTERIE, I., Le sens spirituel de l'Ecriture, p. 627-645.

${ }^{46}$ XXI INCONTRO DI STUDIOSI DELL'ANTICHITÀ CRISTIANA. Cristianesimo Latino e cultura Greca sino al sec. IV. Sobre Ambientes e a produção livresca tardo-antiga: CATALBIANO, M., Litterarum Lumen; SIMONETTI, M., L'Esegesi patrística in Occidente, p. 7-22.
} 
Do outro, este percurso da exegese medieval dos comentaristas e comentários sobre o livro do Apocalipse apontou para a identidade de uma sociedade cristã ameaçada pelo combate entre presente/futuro, entre a Igreja idealizada e aquela sociedade cristã tão rude e ignorante. Mas estes comentários nos falaram de uma fina rede de interpretação semiótica, aquela sobre uma complexa linguagem simbólica e drástica (dragões, demônios, anjos e pragas). ${ }^{47}$

O exercício da construção de uma tradição cristã latina e medieval é um verdadeiro Thesaurus compreensivo para a memória ameaçada deste livro, que por suas fortes características simbólicas, por sua retórica política ( $\mathrm{Da}$ Fiori e os Mendicantes e o fim do mundo), por sua provocação à segurança do establishment eclesiástico e laico (o Anticristo), propôs uma ordem futura ao presente, que (entendia) desinstalar poderes e identidades. A Exegese do Apocalipse medieval resta como um paradigma, para questões que ainda nos espantam, exorcizam e agitam: praeterit enim figura huius mundi (1Cor 7,30).

A modernidade (das Revoluções e da Reforma Protestante) ${ }^{48}$ e sua (pretensa) racionalidade, quando parece ter seus paradigmas esgotados (mal estar), reencontra-se, desde o Romantismo ameaçada pelas leituras tresloucadas das páginas de um Livro que nos seduz a imaginar e desenhar outros percursos da Fé, engendrar outra imagem da Igreja e da Sociedade, entre a Prostituta da Cidade Impura (Ap 17-18) e a Noiva de linho puro (Ap 19), qual Cidade (perfeita) que vem do Céu (Ap 20-22) ou ainda a Mulher (Giné) que enfrenta e vence o Dragão (Ap 12). ${ }^{49}$

\section{Referências bibliográficas}

BAILLY, A. Biblion, to. In: PARASCOLAIRE, H. (Ed.). Dictionnaire Grec Français. 26.ed. Paris: Hachette, 1963. p. 359.

BEDA, O VENERÁVEL. Commento all'Apocalisse. Roma: Città Nuova, 2015.

${ }^{47}$ KAPPLER, C., Monstros, Demônios e Encantamentos no Fim da Idade Média. Estupendo o texto de DIDI-HUBERMAN, G., Atlas ou o gaio Saber Inquieto. Sob outro ponto de vista, as complexas relações entre religião, horror, arte e política (propaganda).

${ }^{48}$ HILL, C. A Bíblia Inglesa e as Revoluções do século XVII.

${ }^{49}$ MATTER, The Apocalypse in the Early Medieval Exegesis. p. 50: "Yet it si also in the twelfth century that the future of Apocalypse exegesis begins to chance, when the apocaliptic themes of Christian symbolism gain precedence over the ecclesiological symbolism that dominated the earlier period and when this shift to the apocalyptic begins to affect even even Latin commentary on the Apocalypse". 
BERARDUCCI, A. L'Esegesi della Rinascita Carolingia. In: CREMASCOLI, G.; LEONARDI, C. (Eds.). La Bibbia nel Medio Evo, Bologna: EDB, 1996. p. 167-198.

BIGUZZI, G. In cerca di punti ondivisibili per per l'interpretazione dell'Apocalisse. In: ALETTI, J. N.; SKA, J. L. (Eds.). Biblical Exegesis in Progress. Old and New Testament Essays. Roma: Istitutto Biblico, 2009. p. 501-528.

BORNKMANN, G. Die Kompositon der apokalyptischen Visionen in der Offenbarung Johannis. Zeitschrift für die Neutestamentliche Wissenchaft, n.36, p. 132-149, 1937.

BREMMER, J. N. The Visio Pauli and the Gnostic Apocalypse of Paul. Leuven: Peeters, 2007.

BURR, D. Mendicant Readings of the Apocalypse. In: EMERSON, R. K.; MCGINN, B. (Orgs.). The Apocalypse in the Middle Ages. London: Cornell, 1992. p. 89-104.

CAMPBELL, G. Antithetical Feminine-Urban Imagery and a Tale of two Women-Cities in the Book of Revelation. Tyndale Bulletin, v.55, n.1, p. 81108, 2004.

CATALBIANO, M. Litterarum Lumen. Ambienti Culturali e Libri trai 1 IV e il V secolo. Roma: Patristicum, 1996.

CAVALLO, G. Libri e lettori nel Medioevo. Guida storica e critica. 5.ed. Roma / Bari: Laterza, 2003.

CAVALLO, G. Le Biblioteche nel mondo antico e medieval. Roma / Bari: Laterza, 2004.

CAVALLO, G.; CHARTIER, R. Storia della Lettura. Roma / Bari: Laterza, 2004.

CHARTIER, R. A Escrita da História. 2.ed. Rio de Janeiro: Forense, 2000.

CHARTIER, R. Uma Variante: a edificação Hagio-gráfica. In: CHARTIER, R. A Escrita da História. 2.ed. Rio de Janeiro: Forense, 2000. p. 266-280.

CREMASCOLI, G.; LEONARDI, C. (Eds.). La Bibbia nel Medioevo. Bologna: EDB, 1996.

XXI INCONTRO DI STUDIOSI DELL'ANTICHITÀ CRISTIANA. Cristianesimo Latino e cultura Greca sino al sec. IV. Roma: Patristicum, 1993. (Studia Ephemeridis Augustinianum, 42). 
DAHAN, G. Lire la Bible au Moyen Âge. Essais d'Hermeneutique Médiévale. Génève: Droz, 2009.

DE LA POTTERIE, I. Le sens spirituel de l'Ecriture. Gregorianum, v.78, n.4, p. 627-645, out./dez. 1997.

DE LUBAC, H. Exégèse médiévale, les quatre sens de l'écriture. Paris: Aubier, 1959. t.1.

DE LUBAC, H. Exégèse médiévale, les quatre sens de l'écriture. Paris: Aubier, 1959. t.2.

DEVUN, L. Prophecy, Alchemy and the End of Time. Paper edition. New York: Columbia, 2014.

DIDI-HUBERMAN, G. Atlas ou o gaio Saber Inquieto. Belo Horizonte: UFMG, 2018.

DINZELBACHER, P. Visio S. Pauli: circulation et influence d'un apocryphe eschatologique. Disponível em: <https://www.brepolsonline.net/doi/ pdf/10.1484/J.APOCRA.2.301294>. Acesso em: 01 fev. 2019.

DUBY, G. A Idade Média. In: DUBY, G.; LACLOTTE, M. História Artística da Europa. São Paulo: Paz e Terra, 1997-1998. t.1.

DUBY, G. A Idade Média. In: DUBY, G.; LACLOTTE, M. História Artística da Europa. São Paulo: Paz e Terra, 1997-1998. t.2.

DULAEY, M. Victorin de Poetovio. Sur L'Apocalypse. Paris: Du Cerf, 1997. (Sources Chrétiennes, 423).

ELLUL, J. Apocalypses. The Book of Revelation. New York: Seabury Press, 1977.

EMERSON, R. K.; MCGINN, B (Orgs.). The Apocalypse in the Middle Ages. London: Cornell, 1992.

EMMERSON, R. K. The Apocalypse in Medieval Culture. In: EMERSON, R. K.; MCGINN, B. The Apocalypse in the Middle Ages. London: Cornell, 1992. p. 293-332.

FARRER, A. A Rebirth of Images. The making of St. John's Apocalypse. London: Wipf \& Stock Pub, 1949.

FERRI, M. Il commento all'Apocalisse dei mss. Cremona. Disponível em: $<$ http://ecodicibus.sismelfirenze.it/uploads/4/8/487/Apocalisse_Ferri.pdf $>$. Acesso em: 10 fev. 2019. 
FONTAINE, J. Comment doit-on appliquer la notion de genre littéraire à la Littérature latine chrétienne du $\mathrm{IV}^{\mathrm{o}}$ siècle? Philologus, v.132, n.1, p. 53-73, 1988.

FOSSIER, R. As Pessoas da Idade Média. Petrópolis: Vozes, 2018.

FOSSIER, R. O Trabalho na Idade Média. Petrópolis: Vozes, 2018.

FREDRIKSEN, P. Tyconius na Augustine on the Apocalypse. In: EMERSON, R. K.; MCGINN, B. (Eds.). The Apocalypse in the Middle Ages. London: Cornell, 1992. p.20-37.

GINZBURG, C. Medo, Reverência, Terror. Quatro ensaios de iconografia politica. São Paulo: Companhia das Letras, 2014.

GRYSON, R. Les commentaires patristiques latins de l'Apocalypse (suite et fin). Revue théologique de Louvain, v.28, n.4, p. 484-502, 1997.

GUGLIELMETTI, R. E. Deux témoins inédits de la Visio Pauli. Disponível em: <https://www.brepolsonline.net/doi/pdf/10.1484/J.APOCRA.5.109944>. Acesso em: 01 fev. 2019.

GUGLIELMETTI, R. E. L'Apocalisse nel Medioevo. Atti del Convegno internazionale dell'Università degli studi di Milano e della Società Internazionale per lo Studio del Medioevo Latino (S.I.S.M.E.L.). Gargnano sul Garda, 18-20 maggio 2009. Disponível em: <http://www.academia. edu/5003700/L_Apocalisse_nel_Medioevo._Gargnano_sul_Garda_18-20_ maggio_2009_cur._R._E._Guglielmetti_Firenze_SISMEL_-_Edizioni_del_ Galluzzo_2011_Millennio_Medievale_90._Atti_di_convegni_27_pp._671>. Acesso em: 10 fev. 2019.

HARTMANN, J. Exégèse Médiévale. Augustinianum, v.5, n.3, p. 552-553, 1965.

HERZMAN, R. B. Dante and the Apocalypse. In: EMERSON, R. K.; MCGINN, B. The Apocalypse in the Middle Ages. London: Cornell, 1992. p. 398-413.

HILL, C. A Bíblia Inglesa e as Revoluções do século XVII. Rio de Janeiro: Civilização Brasileira, 2003.

HOFFMAN, H.-U. Luther und die johannes-Apokalypse. Tübingen: J. C. B. Mohr, 1982.

JERÔNIMO, Epistola. In: WRIGHT, F. A Select Letters of St. Jerome. 
Cambridge: Loeb Classical Library, 1933.

JIROUŠKOVÁ, L. Die Visio Pauli. Wege und Wandlungen einer orientalischen Apokryphe im lateinischen Mittelalter. Unter Einschluß der alttsechischen und deutschsprachigen Textzeugen. Leuven: Brill, 2006.

KAPPLER, C. Monstros, Demônios e Encantamentos no Fim da Idade Média. São Paulo: Martins Fontes, 1994.

LE GOFF, J. A Idade Média e o Dinheiro. Rio de Janeiro: Civilização Brasileira, 2014.

LE GOFF, J.; SCHMITT, J.-C. Dicionário Temático do Ocidente Medieval. São Paulo: EDUSC, 2002. t.1.

LE GOFF, J.; SCHMITT, J.-C. Dicionário Temático do Ocidente Medieval. São Paulo: EDUSC, 2002. t.2.

LERNER, R. Medieval Prophecy and Religious Dissent. Past \& Present, n. 72 , p. 3-24, 1976.

LERNER, R. E. The Medieval Return to the Thousand-Year Sabbath. In: EMERSON, R. K.; MCGINN, B. The Apocalypse in the Middle Ages. London: Cornell, 1992. p. 51-71.

LOBRICHON, G. Gli Usi della Bibbia. In: CAVALLO, G.; LEONARDI, C.; MENETES, E. (Dir.)., Lo Spazio letterario del Medioevo. Roma: Salerno Editrice, 1993. p. 523-562. v.I/2.

LOBRICHON, G. La femme d'Apocalypse 12 dans l'exégèse du haut Moyen Âge latin. In: IOGNA-PRAT, D.; PALAZZO, D.; RUSSO, D. (Dir.). Marie. Le culte de la Vierge dans la société médiévale. Paris: Beauchesne, 1996. p. 407-439.

LOBRICHON, G. L'Esegesi Biblica. Storia di un genero Letterario (VII-XIII secolo). In: CAVALLO, G. (Ed.). Lo Spazio Letterario del medioevo. La produzione del Testo. Roma: Salerno Editrice, 1993. p. 355-381. v.I/2.

MCGINN, B. Joachim of Fiori. In: McGINN, B. Visions of the End. Apocalyptic Traditions in the Middle Ages. Ney York: Columbia Press, 1979. p. 126-142.

MAGGIONI, G. P. La Bibbia nella Lettura Visionaria. In: CREMASCOLI, G.; LEONARDI, C. (Eds.). La Bibbia nel Medioevo. Bologna: EDB, 1996. p. 377-388. 
MANGUEL, A.; GUADALUPI, G. Dicionário de Lugares Imaginários. São Paulo: Companhia das Letras, 2003.

MANGUEL, A. Lendo Imagens. São Paulo: Companhia das Letras, 2001.

MARIN, M.; GIRARDI, M. (Cur.). Retorica ed Esegesi Biblica. Il Rilievo dei contenuti atraverso le forme. Bari: Edipuglia, 1996. (Quaderni di "Vetera Christianorum", 24).

MARJORIE, R. Joachim of Fiore and the Prophetic Future. New York: Harper \& Row, 1977.

MARRONE, P. La continuità esegetica che caratterizza le opere di Ticonio ovvero l'applicazione delle "Regole" nel "Commento all'Apocalisse". Studi e Materiali di Storia delle Religioni, n.67, p. 253-270, 2001.

MARUCCI, C. La canonicità dell'Apocalisse nel Primo Milennio. In: BOSSETI, E.; COLLACRAI,A. (Cura). Apokalypsis. Percorsinell'Apocalisse di Giovanni. Assisi: Cittadella, 2005. p. 649-666.

MATTER, A. E. The Apocalypse in the Early Medieval Exegesis. Disponível em: < https://books.google.com.br/books?id=KV3X s Vpwx 1oC\&printsec $=$ frontcover $\&$ hl $=$ pt-BR\&source=gbs_ge_ summary_r\&cad $=0 \# \mathrm{v}=$ onepage $\& \mathrm{q} \& \mathrm{f}=$ false $>$. Acesso em: $11 \mathrm{fev} .2019$.

MATIS, H. W. The Song of Songs in the Early Middle Ages. Leuven: Brill, 2019.

MCGINN, B. Beatus of Liébana. In: MCGINN, B. Visions of the End. Apocalyptics Traditions in the Middle Age, New York: Columbia Press, 1979. p. 77-80.

MCGINN, B. John's Apocalypse and the Apocalyptic Mentality. In: EMERSON, R. K.; MCGINN, B. (Orgs.). The Apocalypse in the Middle Ages. London: Cornell, 1992. p. 3-19.

MCGINN, B. The Calabrian Abbot. New York: London, 1985.

MCGINN, B. Visions of the End. Apocalyptic Traditions in the Middle Ages. New York: Columbia Press, 1979.

NARI, M. C. La Bibbia ed Eretici nel Pieno Medioevo. La Bibbia nel Medioevo. Bologna: EDB, 1996.

OLIVAR, A. Liber Infernalis o Visio Pauli. Disponível em: $<$ https://www. brepolsonline.net/doi/pdf/10.1484/J.SE.2.303313>. Acesso em: 01 fev. 2019. 
PACZKOWSKI, K. M. Alcuni Aspetti Teologici dell'Apocalisse in Vittorino de Petovio. Biblica et Patristica Thoruniensia, v.5, p. 171-206, 2012.

PANI, G. L'Anticristo nel Commento all'Apocalisse di Vittorino di Petovio. In: BOSSETI, E.; COLLACRAI, A. (Cur.). Apokalypsis. Percorsi nell'Apocalisse di Giovanni. Assisi: Cittadella, 2005. p. 677-702.

PARMEGIANI, R. F. Leituras Medievais do Apocalipse: Comentário ao Beato de Liebana. Estudos de Religião, v.23, n.36, p. 107-125, 2009.

PIAZZONI, A. M. L'Esegesi Vittorina. In: CREMASCOLI, G.; LEONARDI, C. (Eds.). La Bibbia nel Medioevo. Bologna: EDB, 1996. p. 239-256.

PINHO, A. Quinto Império, messianismos: Padre Antônio Vieira e a cultura popular tradicional luso-afro-brasileira. Convergência Lusíada, n.30, p. 121131, 2013.

POTESTÀ, G. L. I frati minori e lo studio della Bibbia. D Francesco D’ Assisi a Nicolò di Lyre. In: CREMASCOLI, G.; LEONARDI, C. (Eds.). La Bibbia nel Medioevo. Bologna: EDB, 1996. p. 269-285.

REEVES, M. The development of Apocalyptic Thought: Medieval attitudes. In: PATRIDES, C. A.; WITTREICH, J. (Eds.). The Apocalypse in English renaissance thought and literature: patterns, antecedentes and repercussions. Mancherster: Mancherster University Press, 1984. p. 40-72.

REEVES, M. The Influence of Prophecy in the Later Middle Ages. An Study in Joachinism. Oxford: University of Notre Dame Press, 1969.

RENNA, T. Avignon vs. Rome: Dante, Petrarch, Catherine of Siena. Expositions, v.4, n.1/2, p. 47-62, 2010.

REVENTLOW, H. G. Storia dell'Interpretazione bíblica. Casale Monferrato: Piemme, 1999. v.3.

REVENTLOW, H. G. Un Monaco in attesa delo Spirito: Giocchino da Fiori. In: REVENTLOW, H. Storia dell'Interpretazione bíblica. Casale Monferrato: Piemme, 1999. p. 236-254. v.2.

ROSSATO, N. D. Evangelium eternum. A hermenêutica condenada de Joaquim de Fiore. Mediaevalia, n.27, p. 99-115, 2008.

ROSSATO, N. D.; MARTINI, M. Milenarismo em Joaquim de Fiore e Antônio Vieira. Mirabilia, n.14, p. 264-28, 2012.

RUSSELL, J. B. Witchcraft in the Middle Ages. London: Cornell, 1972. 
SANTI, F. La Bibbia e la Letteratura profético-apocalittica. In: CREMASCOLI, G.; LEONARDI, C. (Eds.). La Bibbia nel Medio Evo, Bologna: EDB, 1996. p. 389-410.

SANTI, F. La Bibbia in Gioacchino da Fiori. In: CREMASCOLI, G.; LEONARDI, C. (Eds.). La Bibbia nel Medio Evo, Bologna: EDB, 1996. p. 257-268.

SANTOS, P. P. A. A figura feminina de Apoc 12,1-6 : o espaço insólito\} incomum do seu papel estrutural em toda trama narrativa de conflito. Disponível em: <http://www.dialogarts.uerj.br/admin/arquivos_tfc_literatura/ VII_painel_II_enc_nac_simposio_5.pdf $>$. Acesso em: 09 fev. 2019.

SANTOS, P. P. ‘A (Nova) Jerusalém Celeste' (Ap 21,9 - 22,5): Sobre a Cidade Escatológica: uma 'topografia da Salvação' na tradição joanina no Livro do Apocalipse de São João. Atualidade Teológica, v.20, n.53, p. 357386, mai./ago. 2016. Disponível em: <https://www.maxwell.vrac.puc-rio. br/27083/27083.PDFXXvmi=>. Acesso em: 08 fev. 2019.

SANTOS, P. P. A. A Profecia Cristã no Novo Testamento: Uma Tentativa de Reconstrução do fenômeno da Profecia no Cristianismo Primitivo. Atualidade Teológica, v.4, n.6/7, p. 71-102, jan./dez. 2000.

SANTOS, P. P. A. Antigas leituras do Apocalipse na Igreja Grega. Atualidade Teológica, v.18, n.47, p. 274-306, mai/ago. 2014. Disponível em: $<$ https://www. maxwell.vrac.puc-rio.br/23690/23690.PDFXXvmi=>. Acesso em: 05 fev. 2019.

SANTOS, P. P. A. Aspectos teológicos da espiritualidade de Santa Gertrudes: raízes medievais de uma experiência mística e bíblico-teológica. Coletânea, v.17, n.33, p. 47-66, jan./jun. 2018.

SANTOS, P. P. A. O Apocalipse Cristão e os Rolos de Qumran. Literatura e Movimentos apocalípticos no Mundo Antigo e suas relações com Projetos Contemporâneos. Communio, v.22, n.1, p. 133-156, 2004.

SANTI, F. La Bibbia e la Letteratura profético-apocalittica. In: CREMASCOLI, G.; LEONARDI, C. (Eds.). La Bibbia nel Medioevo. Bologna: EDB, 1996. p. 389-408.

SILVERSTEIN, H. T. Dante and the Visio Pauli. Modern Language Notes, v.47, n.6, pp. 397-399, 1932.

SIMONETTI, M. L'Esegesi patrística in Occidente: caratteri e tendenze. In: XXVIII INCONTRO DI STUDIOSI DELL'ANTICHITÀ CRISTIANA. 
L'Esegesi dei Padri Latini. Dalle Origini a Gregorio Magno. Roma: Augustinianum, 2000, p. 7-22. v.1. (Studia Ephemeridis Augustinianum, 68).

SIMONETTI, M. Ticonio e l'interpretazione dell' Apocalisse. In: SIMONETTI, M. Lettera e/o Allegoria. Roma: Augustinianum, 1985. p. 289-305. (Studia Ephemeridis Augustinianum, 23).

TEIXEIRA, A. B. Profecia e Escatologia em António Vieira. Reflexão, v.33, n.93, p. 11-21, 2008.

TOUATI, C. Le problème de l'inerrance prophétique dans la théologie juive du Moyen Age. Revue de l'histoire des religions, v.174, n.2, p. 169-187, 1968.

VANNI, U. Il Simbolismo nell'Apocalisse. Gregorianum, v.61, n.12, p. 461$505,1980$.

VANNI, U. Lingaggio, Simboli ed esperienza misitica nel libro dell'Apocalisse. Gregorianum, v.79, n.3, p. 473-501, 1998.

VANNI, U. L'Uomo dell'Apocalisse. Roma: Apostolato della Preghiera, 2008.

WANNENMACHER, J. E. (Ed.). Joaquin of Fiori and Influence of Inspiration. London: Routledge, 2016.

WILLIAMS, J. The Beatus Commentaries and Spanish Bible Illustrations. In: MAYER, M. (Org.). Actas del Simposio para el estúdio de los códices del "Comentario al Apocalipsis" de Beato de Liebana. Madrid: Joyas Bibliográficas, 1980, p. 101-119. v.1.

WILLIAMS, J. Purpose and Imagery in the Apocalypse Commentary of Beatus of Liébana. In: EMERSON, R. K.; MCGINN, B. (Orgs.). The Apocalypse in the Middle Ages. London: Cornell, 1992. p. 217-233.

XVII INCONTRO DI STUDIOSI DELL'ANTICHITÀ CRISTIANA. Sogni, Visioni e Profezie nell'Antico Cristianesimo. Roma: Patristicum, 1989.

ZIERER, A. M. S; RIBEIRO, J. N. L. Messianismo, Escatologia e Pedagogia cristã na crônica de D. João I. Imagens da Educação, v.3, n. 1, p. 30-43, 2013. 


\section{Pedro Paulo Alves dos Santos}

Doutor em Teologia Biblica pela Pontificia Università Gregoriana Doutor em Letras pela Pontificia Universidade Católica do Rio de Janeiro Docente de Letras no Centro Universitário Unicarioca Rio de Janeiro / RJ - Brasil E-mail: pedosantos@gmail.com

Recebido em: $12 / 03 / 19$ Aprovado em: 08/10/19 